\title{
Making Undergraduate Labs Challenging and Useful
}

\author{
Gridsada Phanomchoeng ${ }^{1,2, *}$, Ratchatin Chancharoen ${ }^{1,3}$, and Ron Lumia ${ }^{4}$ \\ 1 Department of Mechanical Engineering, Faculty of Engineering, Chulalongkorn University, Bangkok \\ 10330, Thailand \\ 2 Applied Medical Virology Research Unit, Chulalongkorn University, Bangkok 10300, Thailand \\ 3 Smart Wireless Communication Ecosystem Research Group, Chulalongkorn University, Bangkok 10300, \\ Thailand \\ 4 Department of Mechanical Engineering, University of New Mexico, Albuquerque, NM, 87131, USA \\ *E-mail: gridsada.p@chula.ac.th (Corresponding author)
}

\begin{abstract}
Learning through laboratory work is critical in high quality science education. Traditional engineering labs are useful but not challenging. However, when the same labs are repeated every year, and students know the results, it is questionable how much is really learned. Students may copy the results from last year's labs, making it difficult for instructors to evaluate their work. To address this problem, the Mechanical Engineering Experimentation and Laboratory II class was revised. A new lab designed to be challenging and useful by using a current research topic to guide it. The class taught in new class environment with state-of-the-art facilities. Students learn instrumentation in a way that forces them to think about the problem, develop a method to measure a phenomenon, and draw conclusions about the results. The tangible connection to research motivates students. It takes professors more time to create these labs. However, since the results fold directly into their research objectives, i.e., gathering data needed for publications, the approach ultimately becomes an efficient use of time. It is fairly common for professors to ignore undergraduate labs, but this paper shows that with a little bit of effort, these labs can provide a significant learning experience for students. Based on the survey, more than $90 \%$ of students agree that the new lab help them to develop defining problem, designing experiment, analyzing, concluding, and reporting skills. More than $70 \%$ of students agree that they learn new measurement equipment for the new lab. Also, $91 \%$ of students would recommend other students to take the new lab. Moreover, this paper shows that the results from the lab lead to the manuscript which has submitted to a journal.
\end{abstract}

Keywords: Experimentation, lab, laboratory, research topic.

ENGINEERING JOURNAL Volume 24 Issue 1

Received 27 August 2019

Accepted 30 October 2019

Published 8 February 2020

Online at http://www.engj.org/

DOI:10.4186/ej.2020.24.1.167 


\section{Introduction}

Learning through laboratory work is essential for science education. A lab experiment introduces new ideas and help students to develop the process of learning skills such as experiment design, data collecting, data analysis, and logical thinking. Moreover, instructors supplement class objectives. For example, students can relate theory and practice, students can develop a new idea and use it to scaffold learning, or instructors can evaluate students with objective measures. The Mechanical Engineering Experimentation and Laboratory II is a class in mechanical engineering that utilizes laboratory work to teach students measurement techniques. This paper describes modifications to the class that benefit both the students and the faculty responsible for the course.

The objective of this class is to teach students to design a lab experiment, conduct the experiment, collect data from measurement equipment, analyze the data, and present results in oral and written forms. The problems assigned to students are selected from theories presented in a companion class. Examples of labs include Vibration of Plates, Air Conditioning Process, and Stress Strain Analysis of a Wing Structure. Even though these problems are useful and relate to the material the students need to understand, these problems are not challenging. This is because the problems have been studied and the procedures to solve the problems are widely known. The students can find the procedures either on-line or from other students, follow the instruction to solve the problems, and learn virtually nothing. For most problems, the students can find the analysis of the data even before performing the experiment. Consequently, the students are not motivated to take these lab classes and obtain minimal benefit. For instructors, evaluation is challenging because it is unknown whether a student actually did the work or just copied the approach from a lab done the previous year. To address this problem, three faculty members radically changed the structure of a lab course. This paper describes the changes, the value to the students taking the class, and the benefits to the professors teaching the class.

\section{Class Environment}

\subsection{3-360 Mechanical Engineering Experimentation and Laboratory II Class}

The class is designed for third year undergraduate mechanical engineering students. It can support up to 40 students. For the class, there are seven learning outcomes: learn knowledge of engineering, apply knowledge in engineering, identify and formulate complex engineering problems, design solutions, investigate complex engineering problems, work as an individual and in teams, and communicate (listen, speak, write, and read) effectively on engineering activities with teams.

This class comprises of four weeks of lecture and five topic labs. Each lab has one professor and one assistant to teach and support students. During the fourweek lecture, students learn measurement instrumentation, experimental process design, and report writing. After that, four to five students form a group. Then, each lab is simultaneously assigned to two group of students. Each group has three weeks to complete a lab. After that, they are rotated to the other labs. To complete the class, each group must finish 3 of 5 labs. The timeline of the class is shown in Table 1.

Table 1. Timeline for the class.

\begin{tabular}{|l|l|l|l|l|l|}
\hline \multirow{2}{*}{ Week } & \multicolumn{5}{|c|}{ Groups } \\
\cline { 2 - 6 } & $\mathbf{1 \& 2}$ & $\mathbf{3 \& 4}$ & $\mathbf{5 \& 6}$ & $\mathbf{6 \& 7}$ & $\mathbf{7 \& 8}$ \\
\hline $1-4$ & Lecture \\
\hline $5-7$ & Lab A & Lab B & Lab C & Lab D & Lab E \\
\hline $8-10$ & Lab E & Lab A & Lab B & Lab C & Lab D \\
\hline $11-13$ & Lab D & Lab E & Lab A & Lab B & Lab C \\
\hline
\end{tabular}

The problems of lab A, B, C, D, and E have traditionally addressed topics such as Vibration of Plates, Air Conditioning Process, or Stress Strain Analysis of a Wing Structure. They have been used to teach in this class more than 10 years. This paper addresses the redesign of Lab A, the only lab changed for the course.

\subsection{Engineering Workspace Facilities}

Lab $\mathrm{A}$ is conducted in the engineering workspace hall $(\mathrm{EWH})$ at Chulalongkorn University, as shown in Figs. 1-3. The EWH is designed to encourage discussion while performing experiments. It has state of the art equipment, such as a SMART board, an interactive whiteboard, which is used to lecture, discuss, and present. There is a space with white boards for group discussion and study. The EWH also provides tools, a laser cutting machine, 3D printers, and measurement equipment students need to execute experiments. Students can freely access the hall during workday from 9.00 to 20.00 . The intent of the EWH is to create an environment that encourages student creativity. 

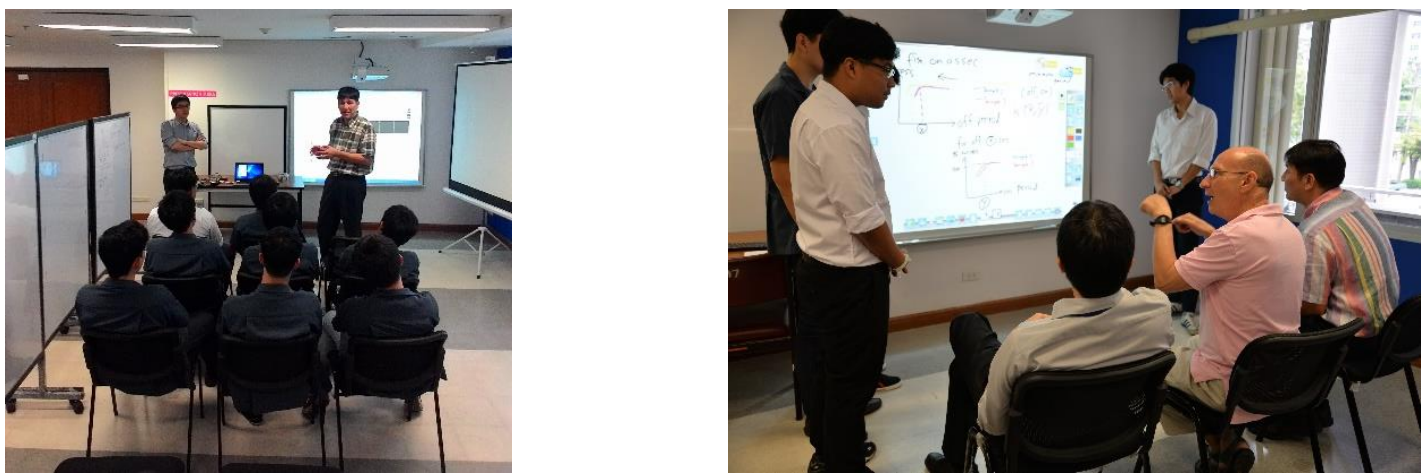

Fig. 1. Space with a SMART board for lecture and presentation.
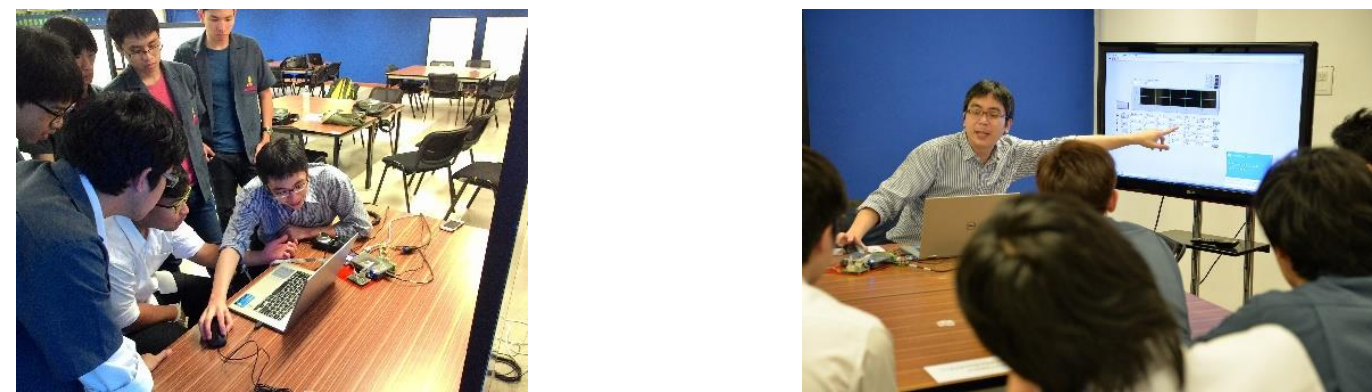

Fig. 2. Space with a large monitor for lecture and demonstration of the equipment.
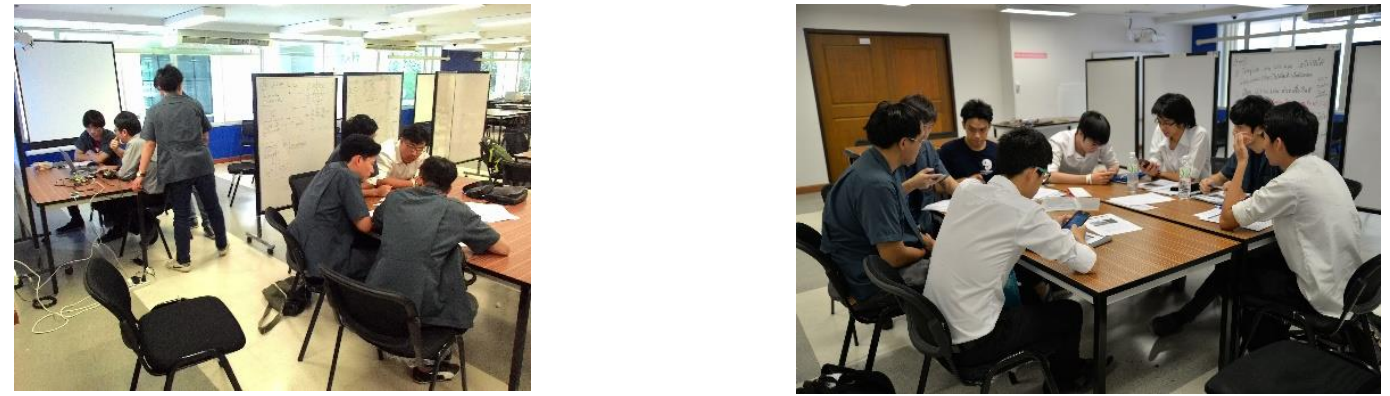

Fig. 3. Space with white boards for group discussion and study.

\section{The Haptic Device}

The traditional lab $\mathrm{A}$ is re-designed around an existing research topic, Developing vibrotactile haptic stimuli based on measured buman capabilities. A vibrotactile wristband, as shown in Figs. 4-5, is designed to send information to the human who wears the device. The wristband consists of four vibration motors that are equally spaced around the wrist. The goal of this research is to investigate the feasibility of sending digital and/or analog signals to a tactile display that are felt by the user. For example, can this device be used to help a blind person navigate through a cluttered environment by "feeling" the proximity of objects? If yes, what parameters should be used to effectively send the data and how many patterns can one send? The lab has three goals:

1. Determine the $\mathrm{ON}$ and OFF periods of a mechanical pulse that a human can sense? Also determine the "best" (students must define what this means) ON and OFF periods that should be used for this application?

2. For a given $1 \mathrm{sec}$ time interval, determine as many patterns as possible that a human can differentiate via the vibrotactile wristband. Note that there are FOUR vibration motors, equally spaced, in the given vibrotactile wristband. Temporal sequences of the vibration motor actuations are encouraged.

3. What is resolution of the signal that a human can sense (instant) using the given vibrotactile wristband?

Two lab groups work in Experiment A during the first lab week. Each group addresses the first goal. For the remaining two weeks, one group works on the second goal while the other addresses the third goal.

In next section, the concept and features of the vibrotactile wristband are presented. Then, the experimental setup and procedures are shown. 


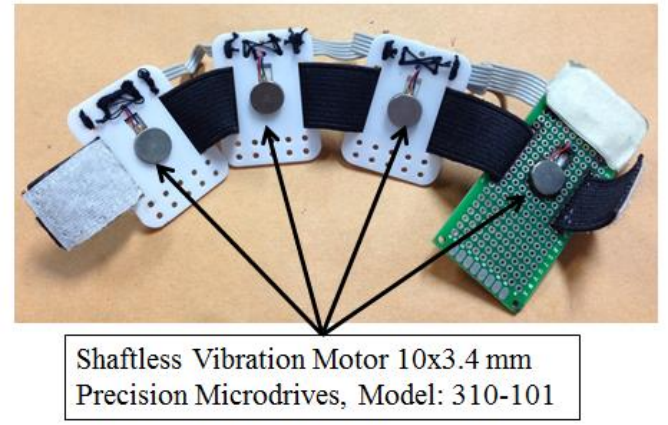

Fig. 4. The design of a vibrotactile wristband.

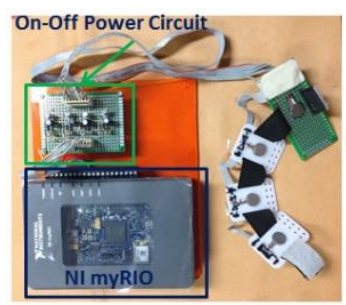

(a)

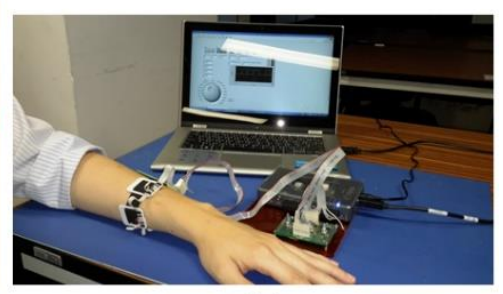

(b)
Fig. 5. (a) NI: myRIO and "on" Off Power Circuit; (b) A vibrotactile wristband with its electronics and interface.

\subsection{Description of the Vibrotactile Wrist-Band}

The device is shown in Fig. 4. The four vibration motors (Precision Microdrive 303-101) are mounted in a slot of plates and attached to an elastic wristband (the width of the wrist-band is about $20 \mathrm{~mm}$ ). The position of the plates can be adjusted to accommodate differences in the size of a human wrist. With this design, most people can easily adjust the wristband to create an equal spacing among the four vibration motors.

The vibration motor has a vibration frequency of approximately $200 \mathrm{~Hz}$ and $0.8 \mathrm{~g}$ acceleration when the input voltage to the motor is between 2.5 to 3.8 volts. This amplitude and frequency are in the comfortable stimulus range for humans [1].

The controller for the vibrotactile wristband consists of a simple "on-off" power circuit using the NI-myRIO with FPGA from National Instruments (NI). The on-off power circuit is controlled by a signal from NI-myRIO and provides 0 or 3.8 volts through a cable to the vibration motors. The NI-myRIO is programmed through LabVIEW 2013 software with Real-Time and FPGA modules. All programs are developed and run on the FPGA to verify that all I/O ports work in parallel. The command update rate is $10,000 \mathrm{~Hz}$. Figure 5 shows the vibrotactile wristband with controller and interface.

\subsection{Experimental Setup}

All experiments were conducted at the EWH at Chulalongkorn University. The professors provide the workspace, instrumentation, and the haptic wristband for the lab. The experiment space is setup as shown in Fig. 6. All test participants were recruited from third year undergraduate students in Mechanical Engineering Department at Chulalongkorn University. Their ages were between 20-22 years and all are healthy. They had previous knowledge about the experiments and felt comfortable with the experiments.

During the first class, the professors introduce the lab, wristband, and instrumentation. They discuss the lab goals with the students. Then, the students explore the instrumentation and brainstorm approaches to achieve the lab goals.

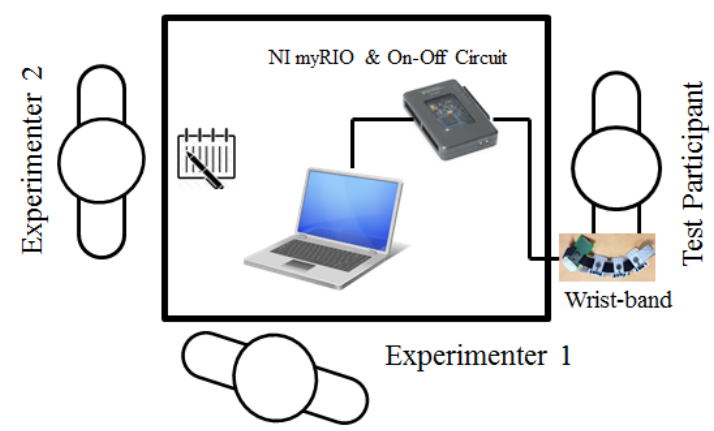

Fig. 6. Top view shows the experiment space.

\subsection{Research Goals}

Based on literature review, there are situations where humans cannot interpret the environment using only sight or hearing. To address this problem, several types of tactile devices have been developed to help humans "visualize" through a haptic interface. For example, references [2-6] have developed directional navigation devices, such as an active belt or wristband. The devices receive directional and range signals from a navigation system, such as GPS. Then, they generate tactile stimuli from multiple vibration motors inside a belt or wristband. Humans can visualize distance and direction though these haptic devices. However, the techniques for generating the stimulus signals for a vibrotactile wristband remain ad hoc. Humans may not perceive the information correctly or they can only receive information at a very low rate. The research need for this lab is that tactile displays need additional investigation.

Therefore, the lab, Developing vibrotactile haptic stimuli based on measured human capabilities, is assigned to the class. A vibrotactile wristband is presented and students conduct the experiment and answer three questions.

1. Find the range of $\mathrm{ON}$ period and $\mathrm{OFF}$ period to trigger the vibration motor such that a human can sense digital data. Also, report on the performance of the commutation. In addition, Find the "optimum" (Students provide the definition of optimum.) ON and OFF periods for this application. Prove that these periods are optimal.

2. Find the number of patterns (sent in one second or less) that can be understood correctly by a human. Determine the performance of the pattern design quantitatively. 
3. Find the resolution of the analog signal that student can send via a vibrotactile wristband.

\section{Generic Methodology to Develop Labs}

1. Decide on research topic of interest that needs experimental data

2. Create open ended questions that require data acquisition (or whatever the goal of the lab is)

3. Prepare measurement equipment and instrument to conduct the experiments (The measurement equipment should be flexible for verity of setup and instrument should be robust.)

4. Write labs handout and prepare materials to help students understand the lab background

5. Introduce the lab to students and let them freely design the experiments.

6. Give students feedback and comments on students' experiment design

7. Prepare the hardware and software setup for students' experiments

8. Let students conduct the experiment and report the results

9. Feedback and comments on the results and report

10. Demonstrate and show students the research gap that they do not understand

11. Modify the open-ended questions after the questions are answered

12. Repeat the process 4 to 11 for other groups

13. Have a final class to conclude what students and professors learn from the lab and what the conclusions of the lab are

\section{Application of Methodology}

\subsection{Guide to Preparing Labs}

There are six groups that perform this lab, scheduled as shown in Table 1. The first round is Group 1 and 2, the second round is Group 3 and 4, and the third round is Group 5 and 6.

Before the lab starts, a hand out and a published paper [2] are given to students to study. During the first class, the professors introduce the lab, the wristband, the measurement instrumentation; they discuss the goals for the lab. There are three goals, as shown in Section 4. Each group needs to address the first goal. Then, one group is selected to conduct the second goal and another one is selected to conduct the third goal. The professors guide them to focus on the first goal that is relatively easy but provides the clues for the remaining goals.

Students explore the instrumentation, do research, and discuss their assignment. They need to design the experiment and present their design experiment to professors before starting the actual experiments. The professors comment on the group's plan and help, as needed, to prepare the setup. Students have three weeks to finish the lab.
Since the questions of the lab are open ended questions and the questions for each group are different, groups are allowed to talk each other, current groups, previous groups, professors, or anyone. The idea is that there are many answers to the questions, and the groups need to formulate a good question before attempting to answer it.

\subsection{Preparing Lab Sequences}

After finishing the three-week lab, the groups are rotated to do another lab and a new group is sent to Lab A. The professors create a new lab based on results of the previous group, which is assigned to the next group. Each group of the current round is encouraged to view the results of previous groups.

\subsection{Lab Assignments}

There are 3 goals for the lab. Since the goals change, each group cannot have the same answers. The assignment for each group is shown below:

1) First Round

1.1) Group 1

- Goal 1: Determine the ON and OFF periods of a mechanical pulse that a human can sense.

- Goal 2: Determine signal patterns for effective communication.
1.2) Group 2

- Goal 1: Determine the ON and OFF periods of a mechanical pulse that a human can sense.

- Goal 3: Determine resolution of the signal that a human can sense (instant) accurately.

2) Second Round
2.1)
Group 3

- Goal 1: Determine the ON and OFF periods of a mechanical pulse that a human can sense.

- Goal 2: Based on the results of Group 1, there are other signal patterns of signal for communication.

\section{2) Group 4}

- Goal 1: Determine the ON and OFF periods of a mechanical pulse that a human can sense.

- Goal 3: Based on the signals designed by creating a sequence of turning on each vibration motor, determine resolution of the signal that a human can sense (instant).

3) Third Round

$$
\text { 3.1) Group } 5
$$

- Goal 1: Base on the results of Group 4, repeat the technique and improve the presentation and analysis of the results of the ON and OFF periods of a mechanical pulse that a human can sense.

- Goal 3: Based on the signals designed by creating a sequence of turning on each vibration motor, develop the technique to improve success rate percentage of discrete steps that a human can sense (instant). 


\section{2) Group 6}

- Goal 1: Based on the results of Group 4, repeat the technique and improve the presentation and analysis of the results of the $\mathrm{ON}$ and OFF periods of a mechanical pulse that a human can sense.

- Goal 3: Based on the signals designed by creating a sequence of turning on each vibration motor, develop the technique to increase resolution of the signal that a human can sense (instant).

Note: For the second round, Goal 3 has been adjusted due to the results of the first round. Also, for the third round, Goal 2 was removed from the lab because it did not appear to add new information.

\section{Results}

Based on class syllabus, student groups needed to submit a full report for the first lab and short reports for the remaining two labs. For the full report, each group had three chances to edit/improve the report. For their second and third lab, students submitted the short report after finishing three-week lab. Thus, Groups 1 and 2 had to submit full reports. The rest submitted only the short reports for their lab experience.

\subsection{First Round Results}

Since the questions of the lab were open ended questions and there was no guideline for the results, the groups needed to think and develop the charts/graphics to present their results by themselves.

\section{Group 1}

For Goal 1, Group 1 had a good idea to determine the ON and OFF periods of a mechanical pulse that a human could sense during a variety of human activity. The results showed that $\mathrm{ON}$ and OFF periods depended on human activity. However, in their first draft, they chose to present the results with the bar charts as shown in Fig. 7. With this format, it is very difficult to interpret their results.

After instructor feedback, they revised their approach and presented their results, as shown in Fig. 8. This time, the important and useful results contained in the graphics were easy to understand.

For Goal 2, they developed signal patterns for communication. The patterns and the results were presented with the symbols and tables as shown in Fig. 9. However, in the final results, they could develop the better format to present these results. Fig. 10 showed the final results of the goal 2. The graphic was more selfcontained.

\section{Group 2}

For Goal 1, this group had a different approach to determine the $\mathrm{ON}$ and OFF periods of a mechanical pulse that a human could sense. They had a hypothesis that the ON and OFF periods might be dependent. Thus, they designed an experiment that was different from that of Group 1. They selected 3D bar chart to present the results. Figure 11 showed the first draft result of Group 2.

Although reporting the result with 3D chart looked impressive at first glance, there were many questions raised by the chart. It was difficult to interpret the results with 3D chart. The professors provided feedback to help them understand their Goal 2 results. The students found a better method to present the result. Figure 12 shows the final results for Goal 2. The 3D bar chart was replaced by a 3D surface and contour plot. These plots, which used the same data, were easy to interpret. However, they were still difficult to apply in practical.

For Goal 3, they could determine number of discrete steps that a human could sense. However, in the first draft, they selected bar chat as shown in Fig. 13 to present the results again. After feedback from the professors, the students revised their presentation approach, as shown in Fig. 14.
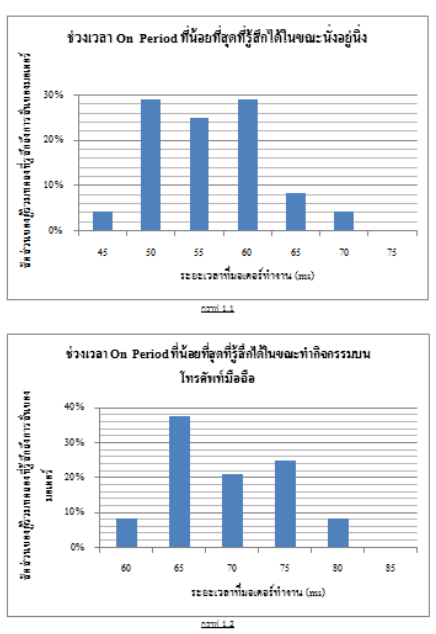

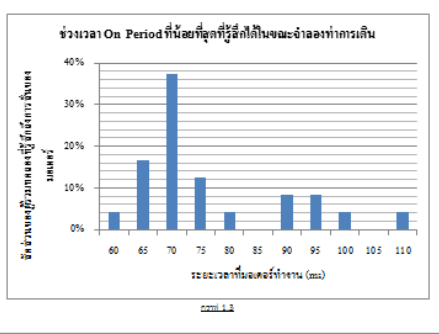

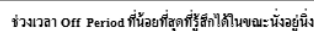

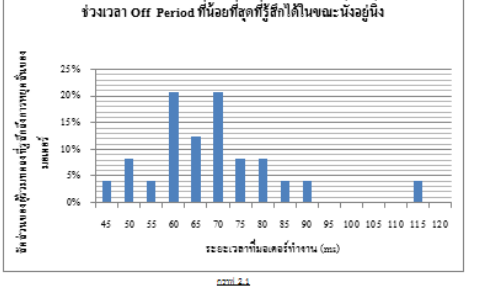

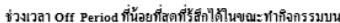

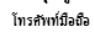
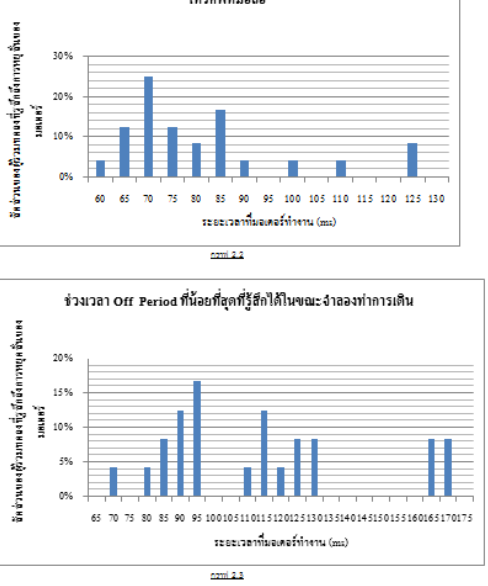

Fig. 7. The first draft result for the goal 1 of Group 1. 


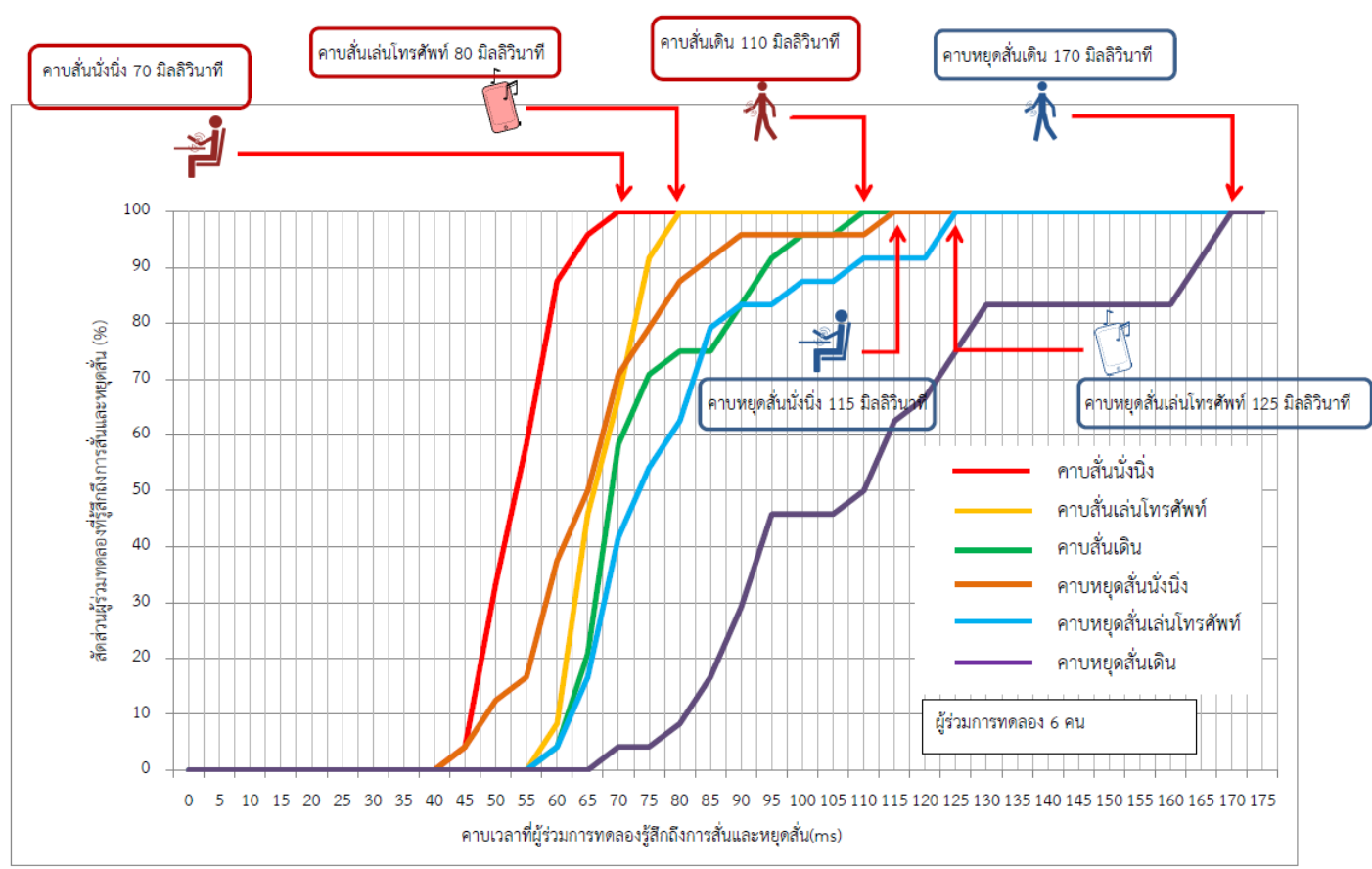

Fig. 8. The final results for the goal 1 of Group 1 .

\begin{tabular}{|c|c|c|}
\hline หมายเลขสัญญาณ & สัญสักษณ์แทนสัญฌาณ & Success rate $(\%)$ \\
\hline 1 & $\bullet$ & 100 \\
\hline 2 & $\bullet \bullet$ & 50 \\
\hline 3 & $\bullet \bullet \bullet$ & 75 \\
\hline 4 & $\bullet \bullet \bullet \bullet$ & 100 \\
\hline 5 & $\bullet$ & 75 \\
\hline 6 & $\bullet \bullet \bullet$ & 75 \\
\hline 7 & $\bullet \bullet \bullet$ & 100 \\
\hline 8 & $\bullet \bullet \bullet$ & 100 \\
\hline 9 & $\bullet$ & 25 \\
\hline 10 & $\bullet$ & 75 \\
\hline 11 & $\bullet$ & 100 \\
\hline 12 & $\bullet$ & 50 \\
\hline
\end{tabular}

ตาราง (2.1) Success rate ของสัญญาณชุดที่หนึ่ง : สั่นพร้อมกันสี่ตัว

\begin{tabular}{|c|c|c|}
\hline หมายเลขสัญญาณ & สัญลักษณ์แทนสัญญาณ & Success rate ( 96$)$ \\
\hline 13 & $\bullet \bullet$ & 100 \\
\hline 14 & $\bullet \bullet \bullet$ & 100 \\
\hline 15 & $\bullet \bullet \bullet \bullet$ & 75 \\
\hline 16 & $\bullet \rightleftharpoons$ & 100 \\
\hline 17 & $\bullet \bullet \bullet$ & 100 \\
\hline 18 & $\bullet \bullet$ & 100 \\
\hline 19 & 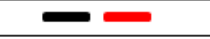 & 75 \\
\hline 20 & 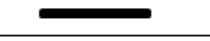 & 75 \\
\hline 21 & 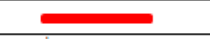 & 50 \\
\hline
\end{tabular}

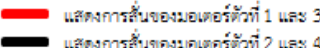

ตาราง (2.2) Success rate ของสัญญาณชุดที่สอง : สั่นเป็นคู่ตรงข้ามสองคู่

\begin{tabular}{|c|c|c|}
\hline หมายเลขสัญญาณ & สัญลักษณ์แทนสัญญาณ & Success rate (\%) \\
\hline 22 & $\bullet \bullet$ & 75 \\
\hline 23 & $\bullet \bullet \bullet$ & 50 \\
\hline 24 & $\bullet$ & 100 \\
\hline 25 & $\bullet$ & 75 \\
\hline 26 & $\bullet \bullet$ & 100 \\
\hline 27 & $\bullet \bullet$ & 25 \\
\hline
\end{tabular}

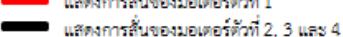

Fig. 9. The first draft result for the goal 2 of Group 1. 
ผลการทดสอบอัตราความสำเร็จ (Success Rate) ของรูปแบบสัญญาณ

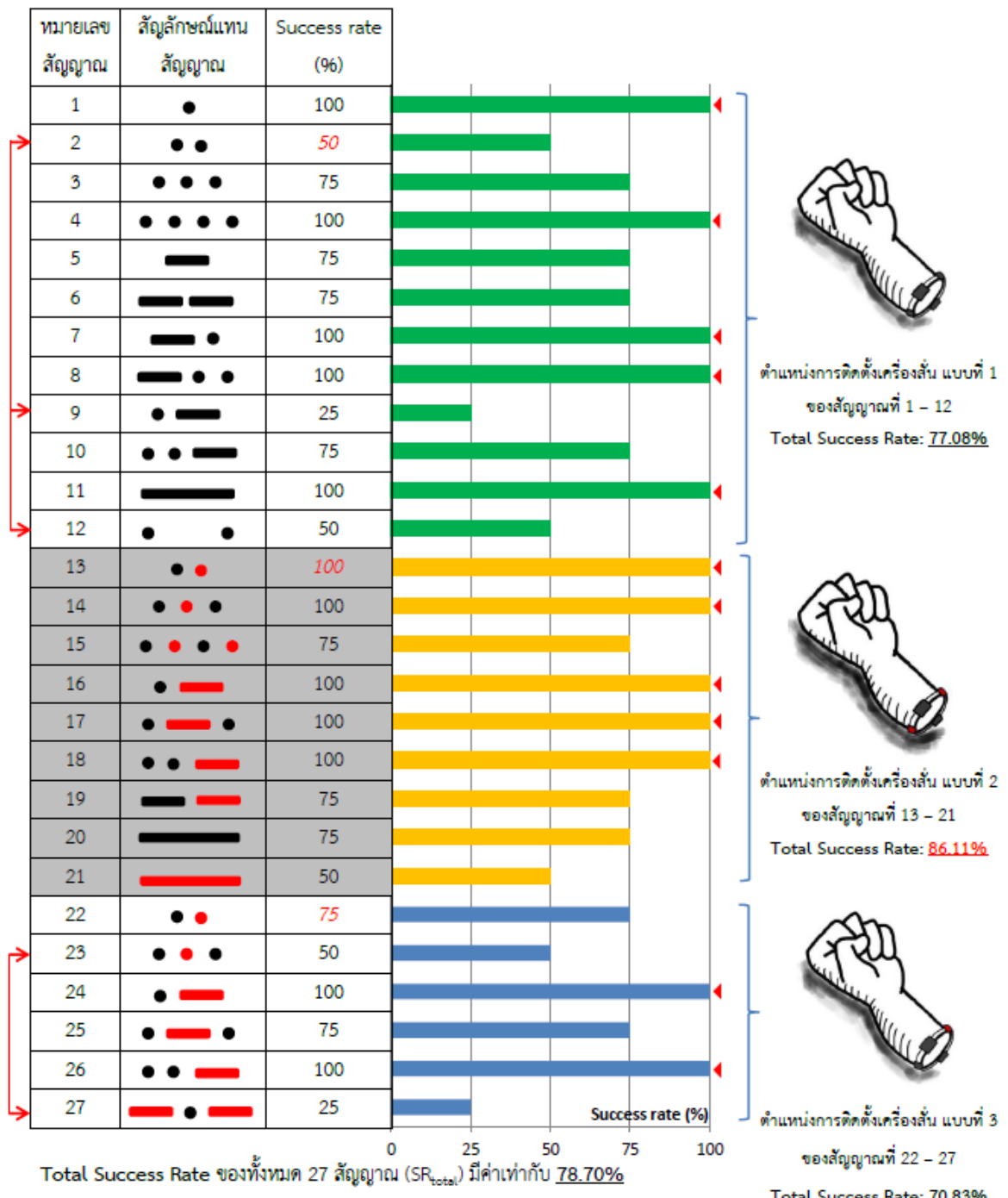

Fig. 10. The final results for the goal 2 of Group 1.

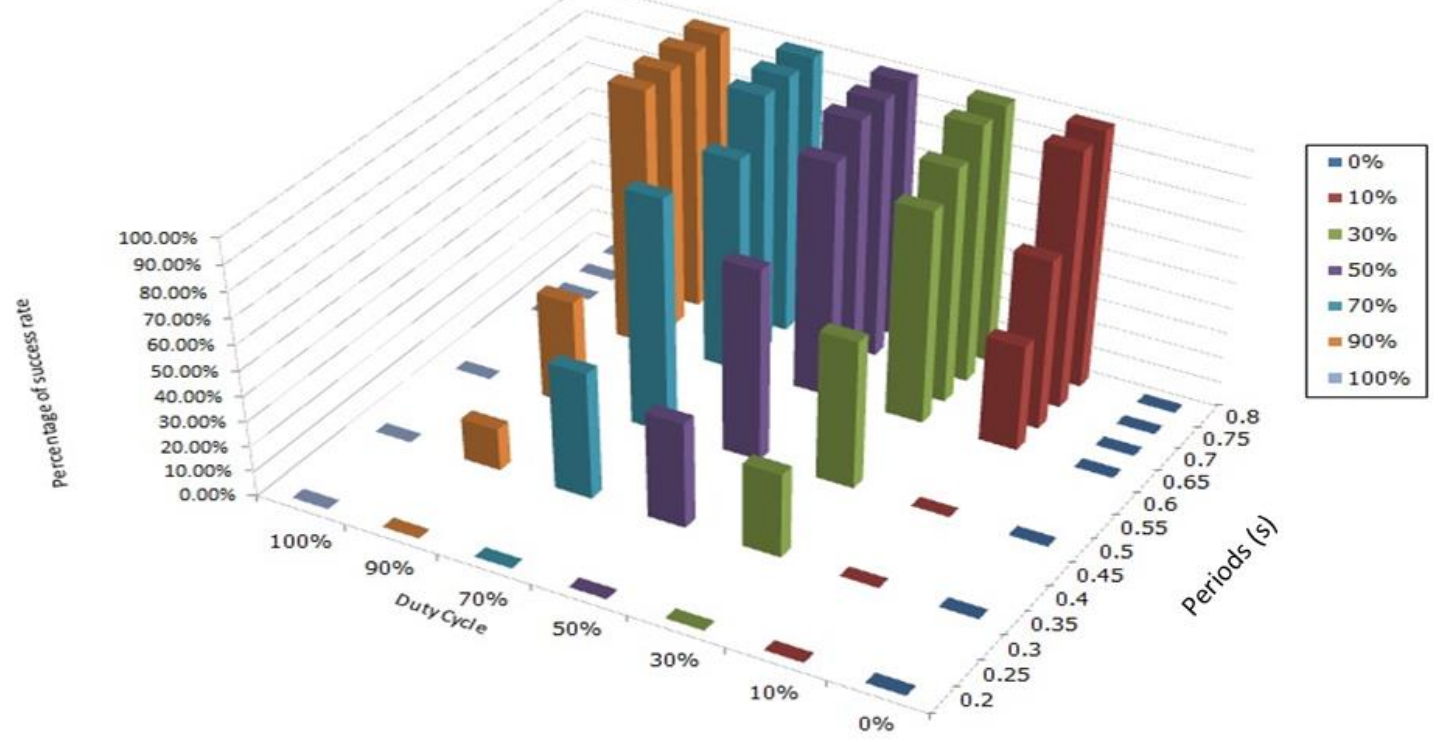

Fig. 11. The first draft result for the goal 1 of Group 2. 


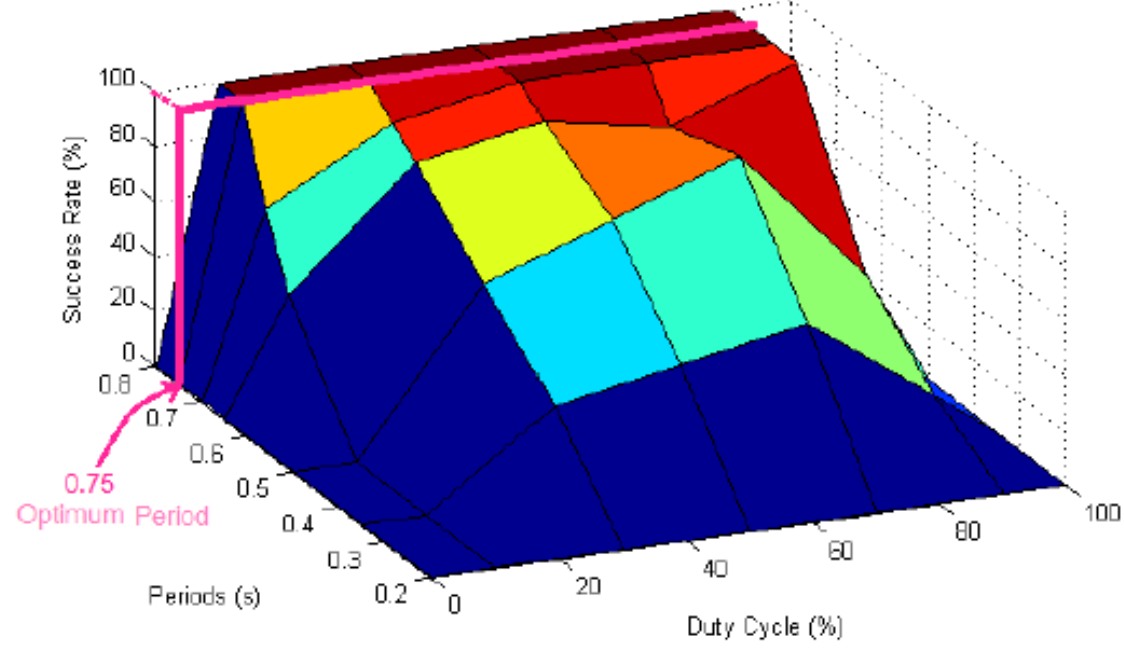

รูปที่ $5 . \mathrm{A}$ ความสามารถในการรับรู้ของมนุษย์จาก Vibrotactile wristband (Surface)

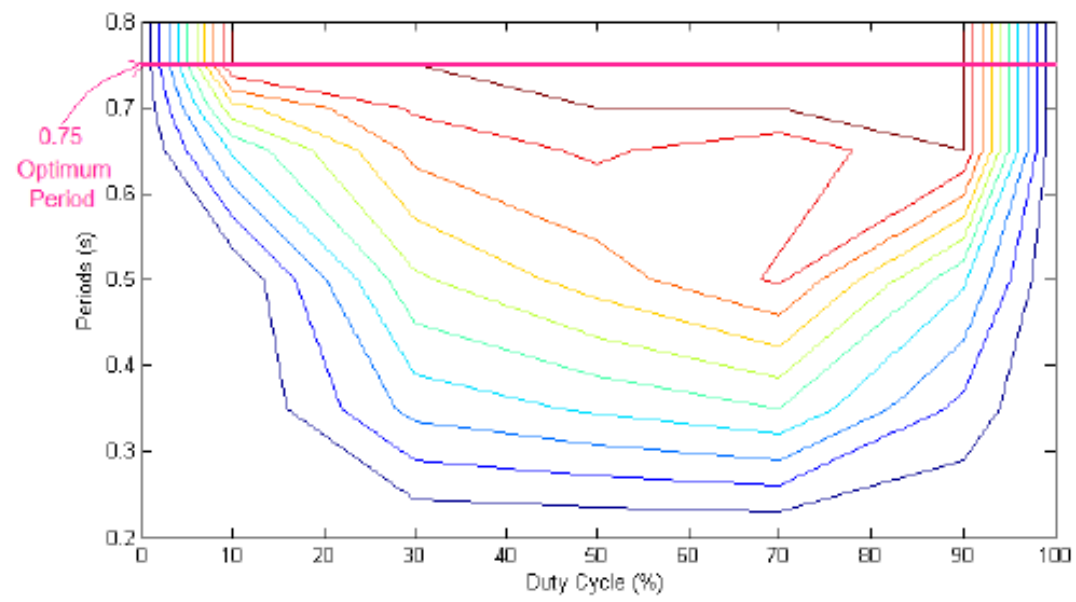

รูปที่ $5 . B$ ความสามารถในการรับรู้ของมนุษย์จาก Vibrotactile wristband (Contour)

Fig. 12. The final results for the goal 1 of Group 2.

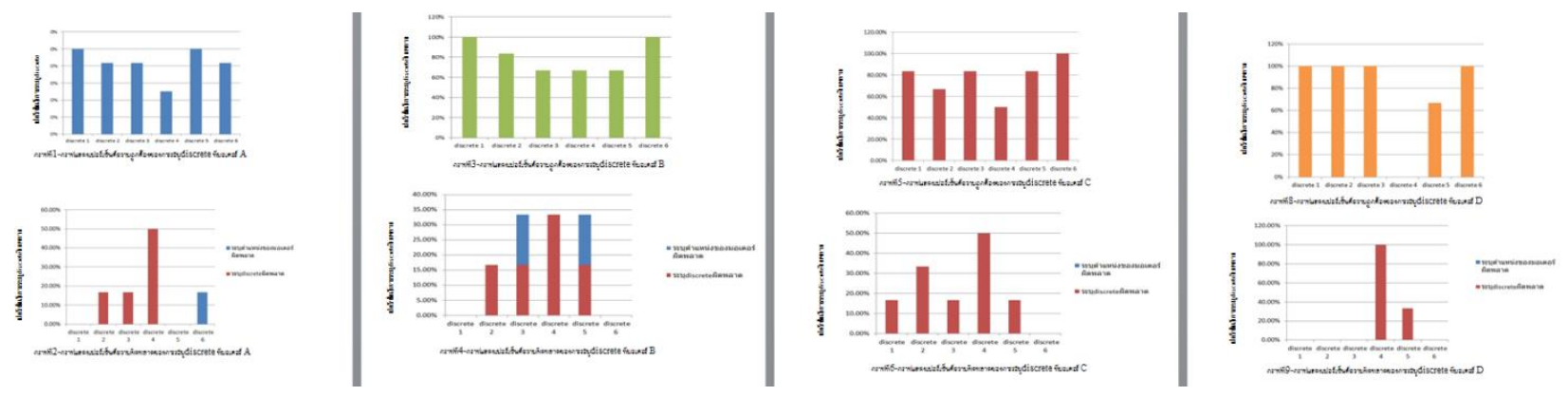

Fig. 13. The first draft result for the goal 3 of Group 2. 


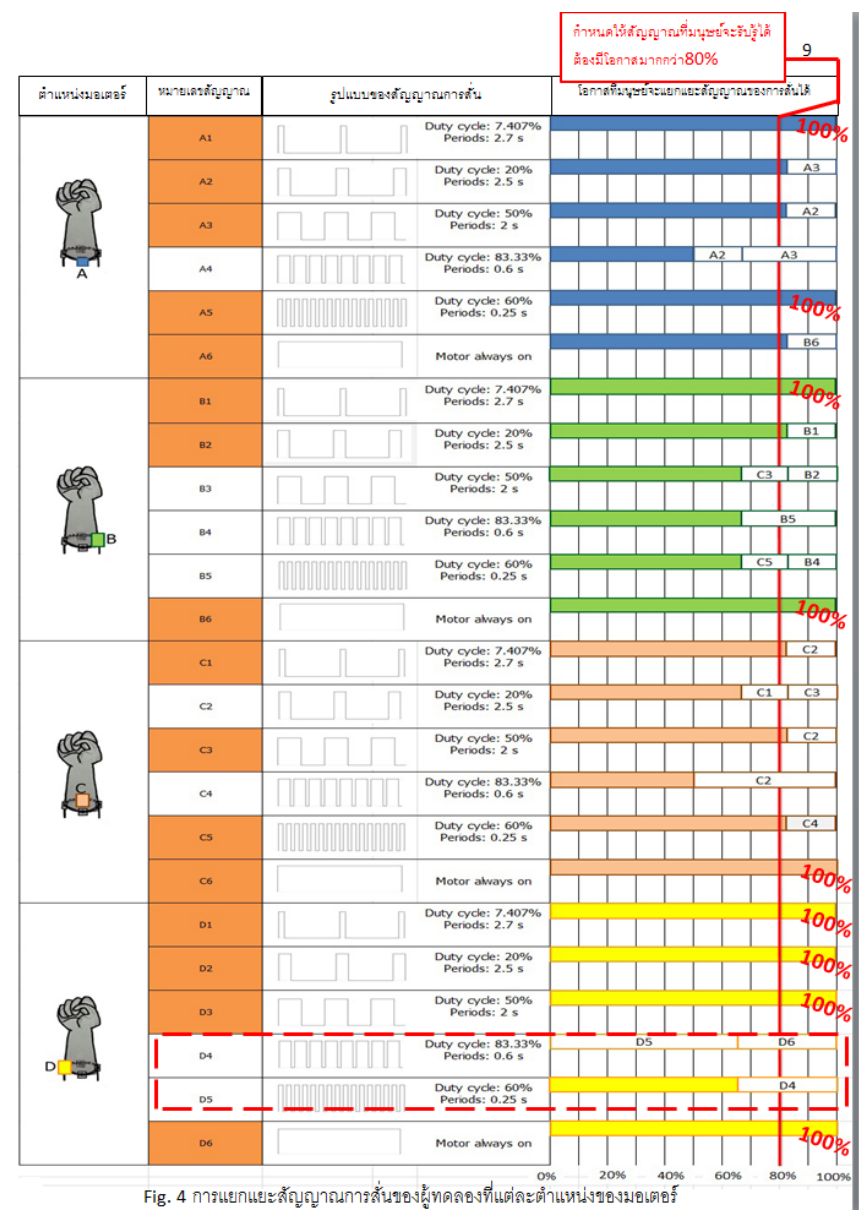

Fig. 14. The final results for the goal 3 of Group 2.

\subsection{Second Round Results}

For the second round, they had a chance to see the results of the previous and to talk with the previous groups. They could use the previous knowledge to develop their experiment.

\section{Group 3}

This group was assigned with Goals 1 and 2. The methods that they used to solve these problems were different from Group 1. However, the results they obtained were pretty much the same as Group 1 . This helped the professors to confirm the results of Group 1. Figures 15 and 16 showed the results of this group.

\section{Group 4}

For Goal 1, this group decided to improve the 3D plot of Group 2. They applied the experiment method of Group 2 and select another way to present the results. Finally, they came up with the contour plot as shown in Fig. 17. This plot looked clear and easy to use and understood. However, the plot was still not complete because it was missing some information.

For Goal 3, they were asked to design the signals created from a sequence of turning on each vibration motor. The method seems ad hoc. However, they could

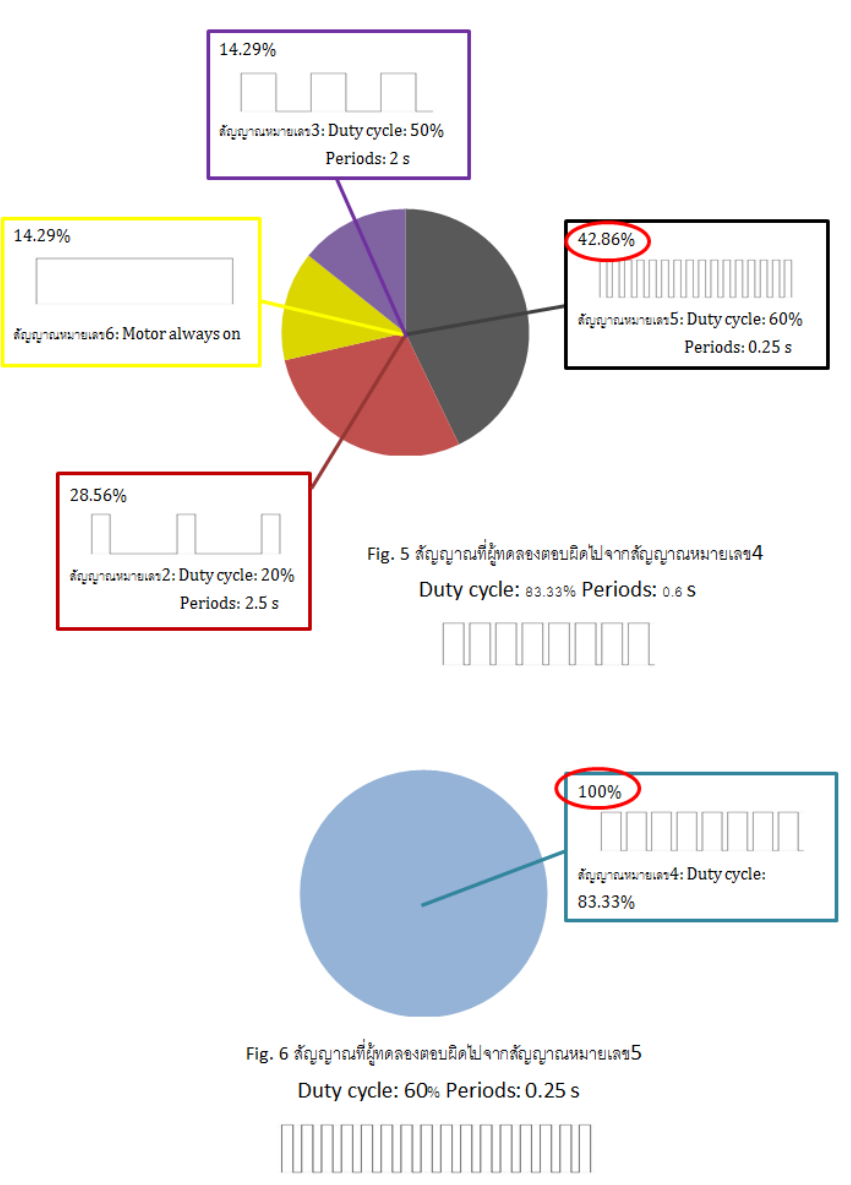

determine these signals. This introduced a new technique for communication that was never published. The result of this goal was shown in Fig. 18.

\subsection{Third Round Results}

Students could see the results of the previous groups and talk with them. They could use the previous knowledge to inform their experimental approach.

\section{Group 5}

For Goal 1, this group was asked to repeat the experiment of Group 4 but they needed to add more information and complete the plot. The plot of this group was shown on Fig. 19. It was improved but still not fully complete.

For Goal 3 of this group, they needed to determine the methods to improve the success rate of the signals developed by Group 4. They analyzed the errors of the signals and developed a method by using a signal base to increase the success rate of the signals. Their results were shown on Fig. 20. 


\section{Group 6}

For Goal 1, this group had the same task to complete the plot of Group 4. Their improved plot is shown in Fig. 21.
For Goal 3 of this group, they needed to determine a method to increase the number of the signals developed by Group 4. They decided to actuate the wristband motors to induce the feeling of rotation direction to increase the number of the signals. Their results are shown in Fig. 22.

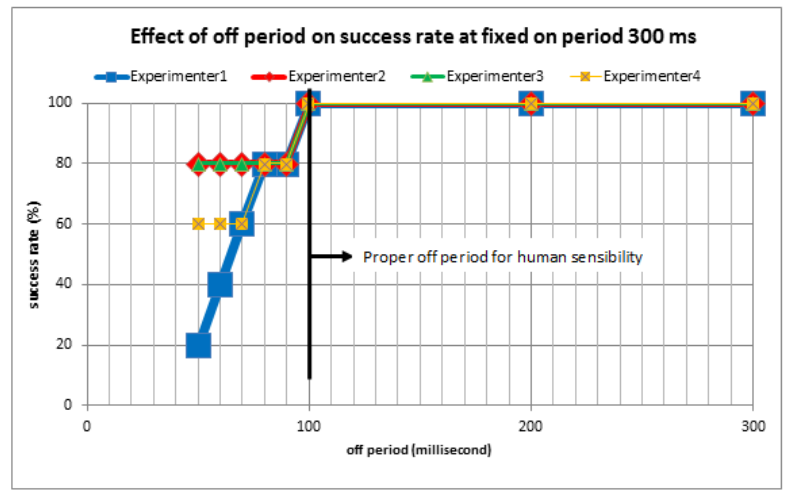

รูปที่ 2.1 กราฟผลของ off period ต่อ อัตราความสำเร็จในการรับรู้ของผู้ทดลองเมื่อ on period มีค่าคงที่ $300 \mathrm{~ms}$

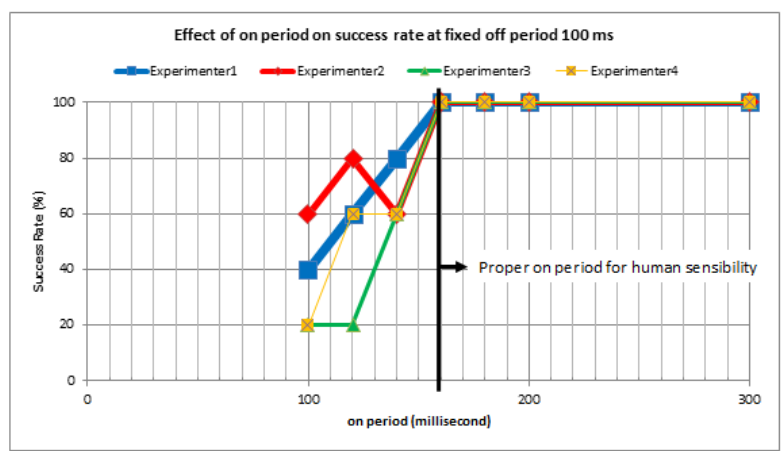

รูปที่ 2.2 กราฟผลของ on period ต่อ อัตราความสำเร็จในการรับรู้ของผู้ทดลองเมื่อ off period มีค่าคงที่ $100 \mathrm{~ms}$

Fig. 15. The result for the goal 1 of Group 3.

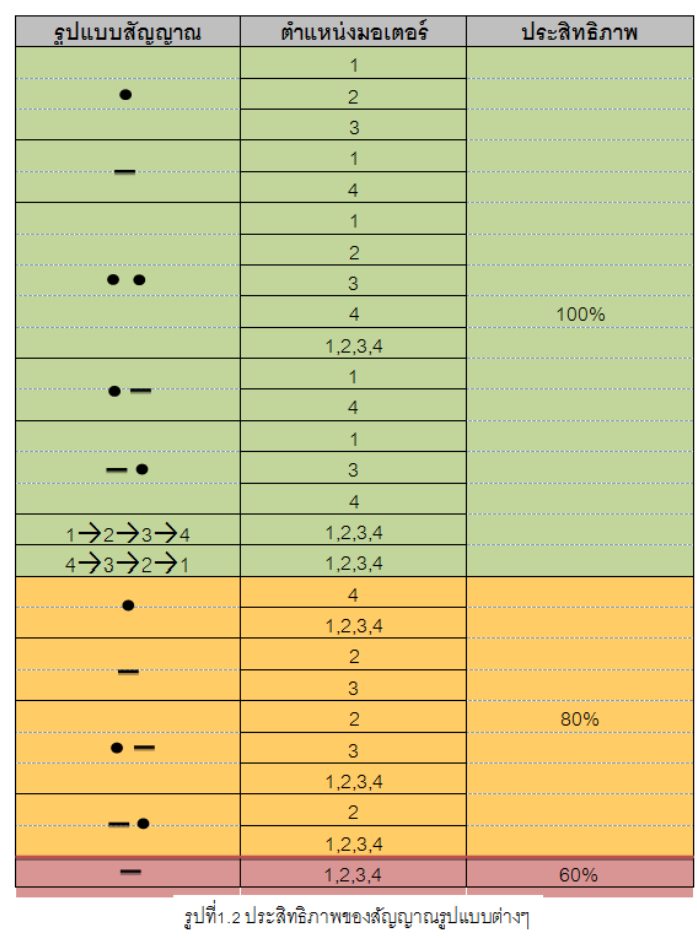

Fig. 16. The result for the goal 2 of Group 3. 


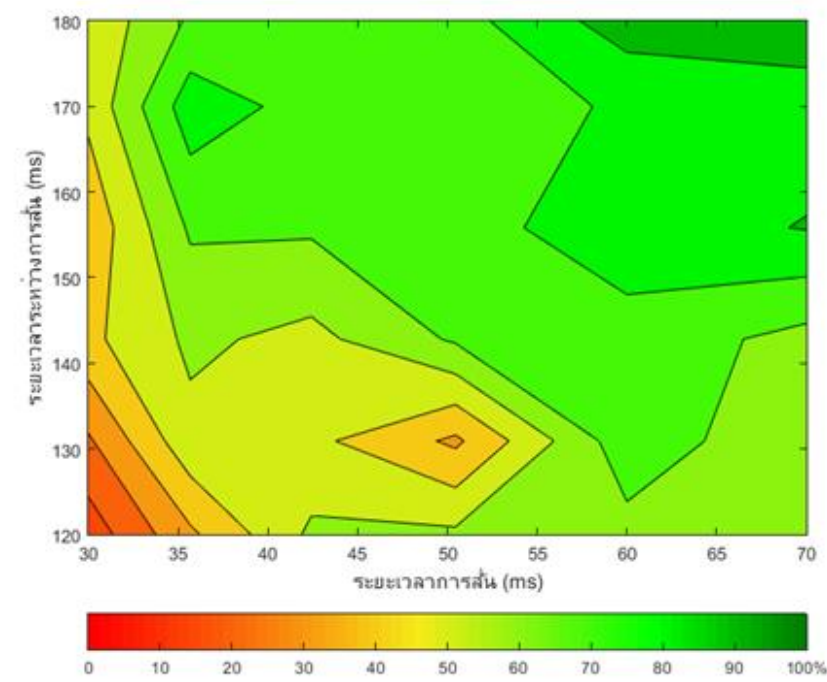

รูปที่ 1 กราฟแสดงความสัมขันธ์ระหว่างการสันในรูปแบบต่างๆกับร้อยละความถูกต้องของคำตอบ

Fig. 17. The result for the goal 1 of Group 4.

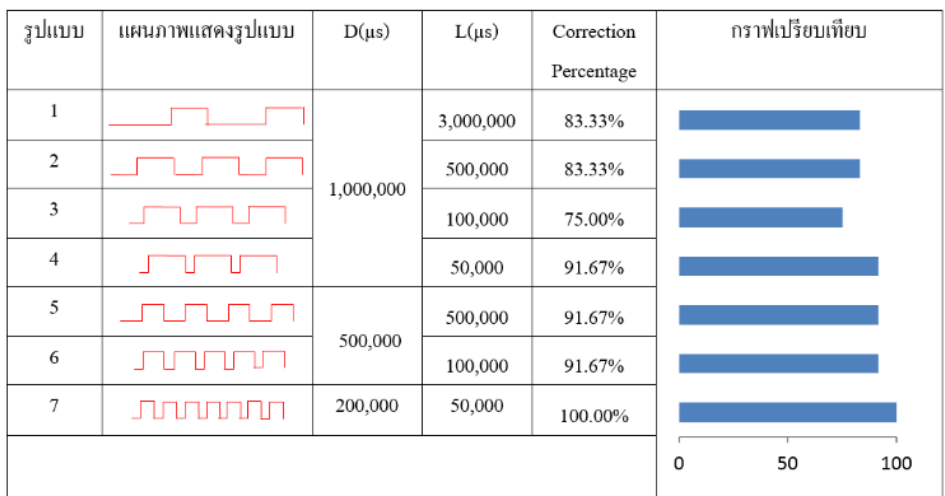

ตารางที่ 2 ตารางแสดงถึงความถูกต้องของระดับขั้นสัญูญามต่างาซึ่งนำไปสู่ผลสรุปว่าวิธี้นีมีปะสิทธิภาพเท่าใด

Fig. 18. The result for the goal 3 of Group 4.

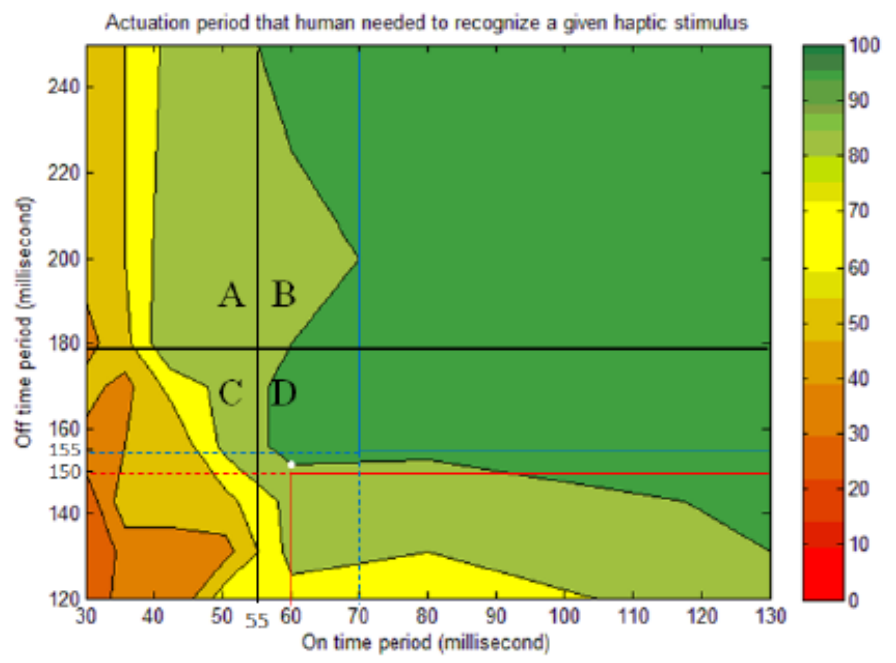

รูปที่ 2 แสดงความถูกต้องของการรับสัญญาณที่เวลาเปิด-ปิดมอเตอร์ต่างกัน

Fig. 19. The result for the goal 1 of Group 5. 


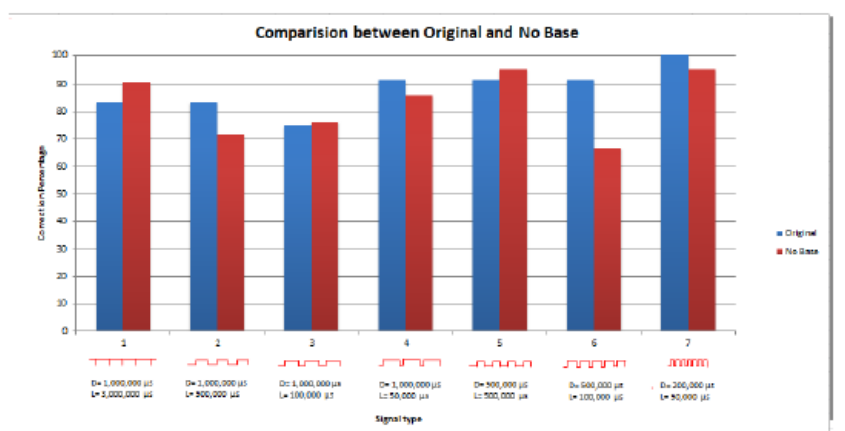

รูปที่ 3 แสดงความถูกต้องของการรับสัญญาณแบบเดิมกับไม่มี base

ตารางที่ 2 แสดงความถี่ของคำตอบที่คลาดเคลื่อน

\begin{tabular}{|c|c|c|c|c|c|c|c|c|c|}
\hline \multirow{2}{*}{ วูปเบบ } & \multirow{2}{*}{ แเผนาพาแสดงูปเนบบ } & \multirow{2}{*}{$\mathrm{D}(\mu \mathrm{s})$} & \multirow{2}{*}{$L(\mu s)$} & \multicolumn{6}{|c|}{ ความถ์ของคำตอบห์่คลาดเคล์อน } \\
\hline & & & & \begin{tabular}{l|l}
1 & 2 \\
\end{tabular} & 3 & 4 & 5 & 6 & 7 \\
\hline 1 & \begin{tabular}{l|l|l|l|l}
1 & 1 & 1 & 1 & 1
\end{tabular} & \multirow{4}{*}{$1,000,000$} & $3,000,000$ & & & & & & \\
\hline 2 & 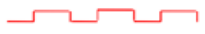 & & 500,000 & & & & - & & \\
\hline 3 & ऽபே & & 100,000 & & & & & \\
\hline 4 & & & 50,000 & $\equiv$ & $\square$ & & & $\Xi$ & \\
\hline 5 & תשூோ & \multirow{2}{*}{300,000} & 500,000 & & $\square$ & & & & \\
\hline 6 & תルルル & & 100,000 & & $\theta$ & & $\exists$ & & \\
\hline 7 & תחתית ת & 200,000 & 50,000 & & & & & & \\
\hline
\end{tabular}

Fig. 20. The result for the goal 1 of Group 5.
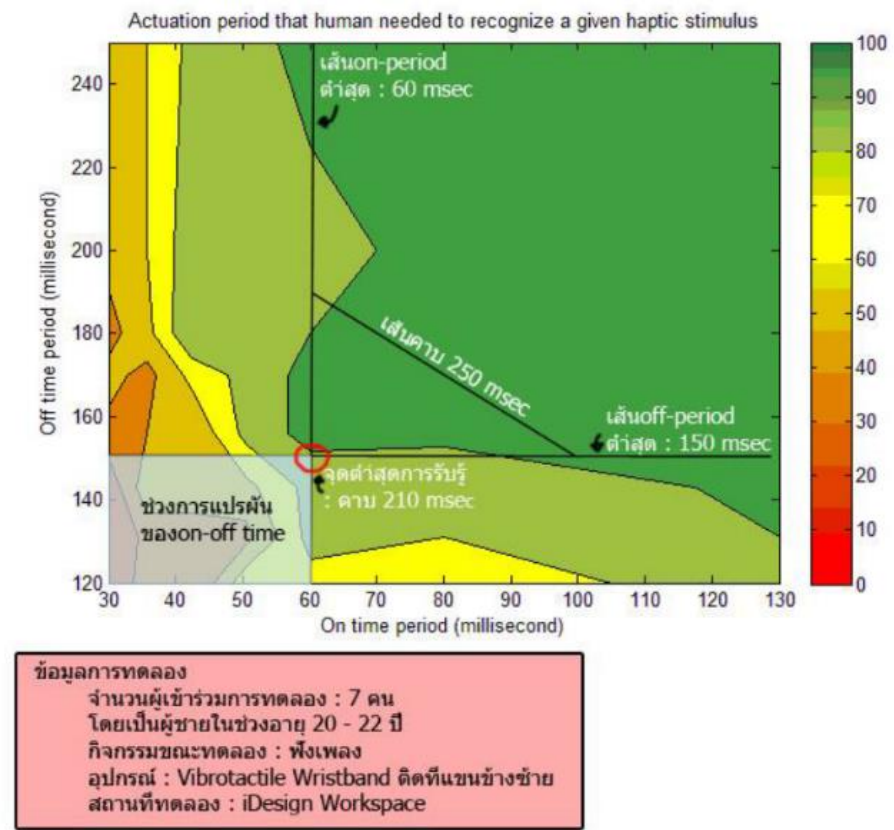

รูปที่ 4 : ความสัมพันธ์ระหว่างการสั่นในรูปแบบกับความถูกต้องของคำตอบที่ได้จากผู้ทดลอง

Fig. 21. The result for the goal 3 of Group 6. 

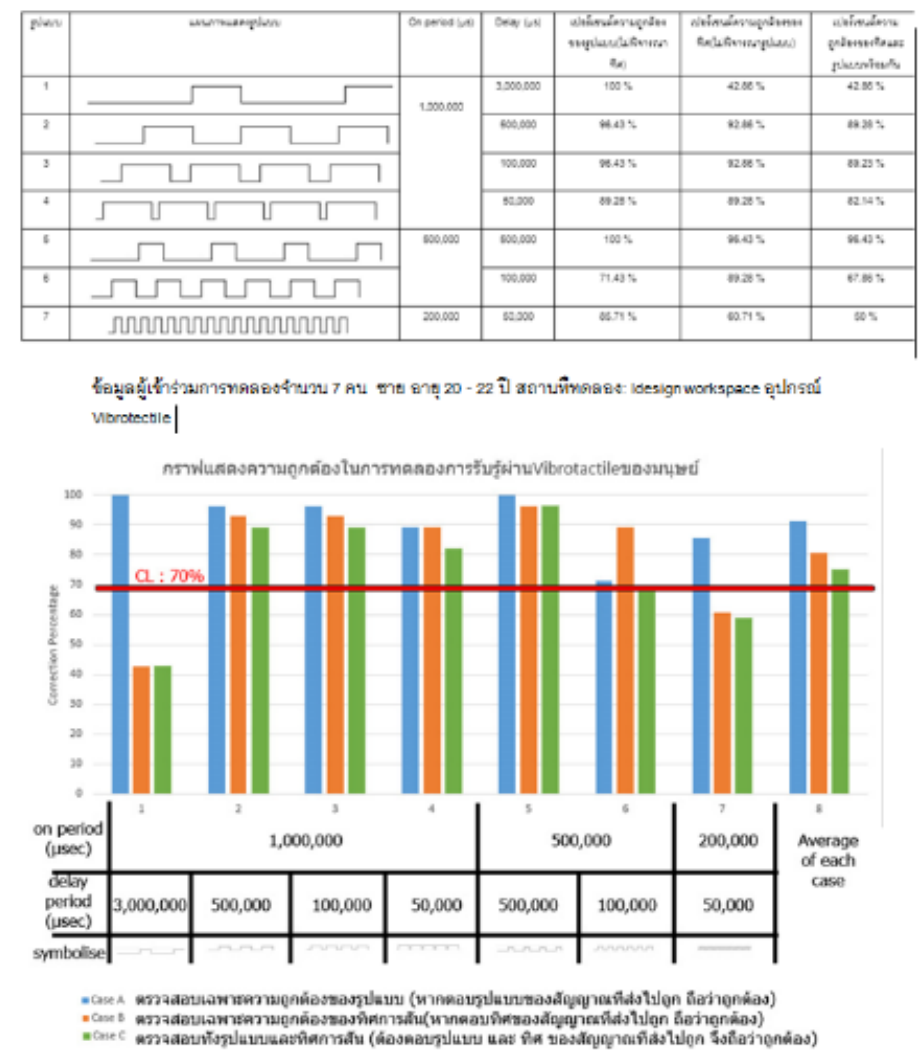

Fig. 22. The result for the goal 3 of Group 6 .

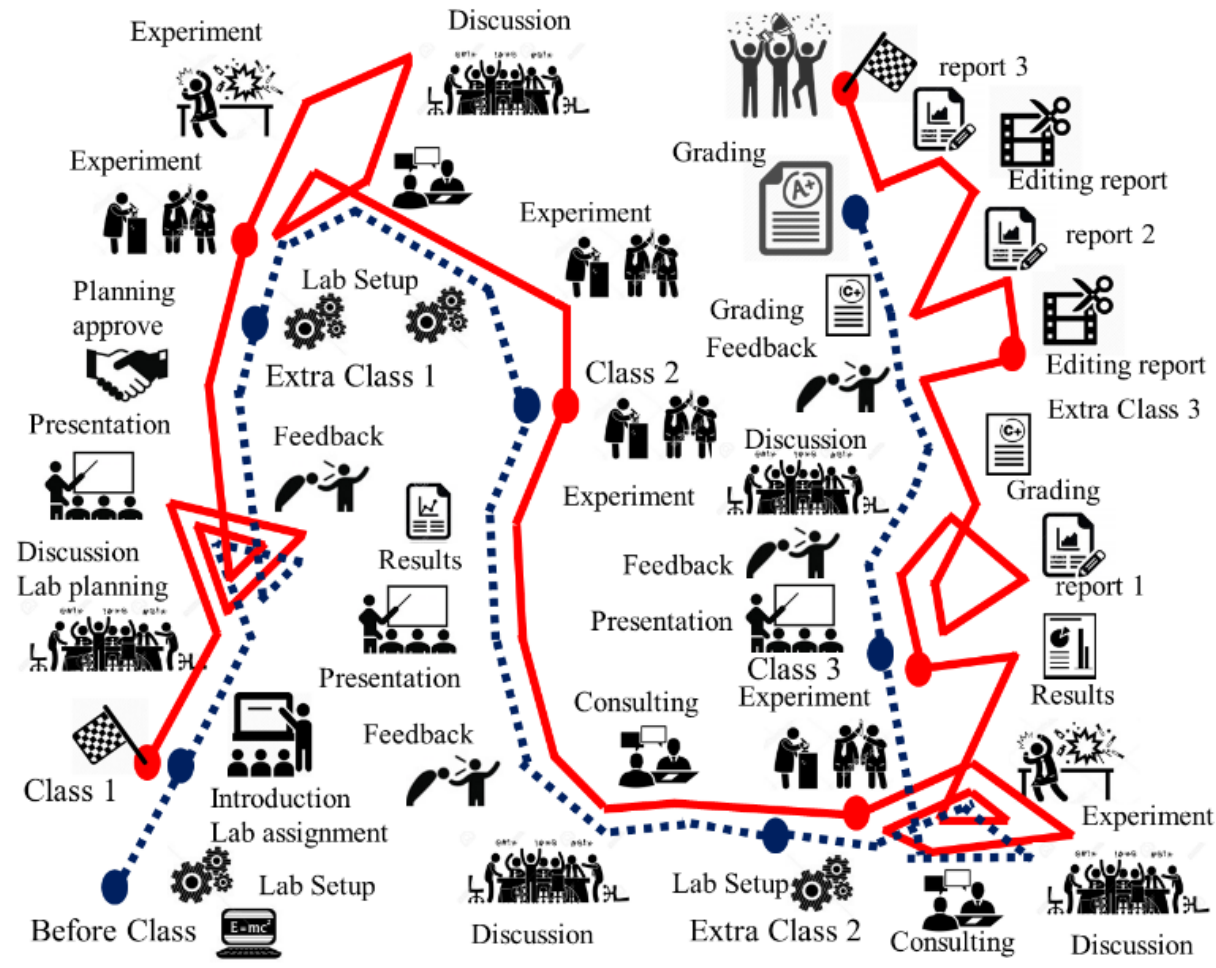

Fig. 23. Students and Professors Journey.

\subsection{Results for Students}

Figure 23 shows the journey followed by the students and professors in the new lab. In this class, students had a chance to work on a research topic. They had to define the problems, define the scope, design the experiments, execute the experiment, analyze the data, and report the results by themselves. Since there was no guideline for the solution for this lab, they needed to research and consult with professors. Moreover, they had to spend a lot of time to do experiment. Also, professors also must devote time to students, help them 
setup the lab, consult, and give feedback. It took more effort for professors to create and run this lab experiment, but when the results folded directly into their research objectives, this became an efficient use of time.

In addition, after the class was done, the professors collected all data, re-analyzed and extracted additional information from students' experimental results. Some student results were simply reformatted. Then, the professors showed the reformatted results and plots to students, noting that no experimental results changed. The only change was how to present the results. As a result, the students had the opportunity to see alternative ways to format the same data, helping them understand what they missed and where what they can improve.

Figures 8 and 10 were examples of the good results that students developed by themselves. The professors could not complain about it. Figure 21 was also a good result but it was incomplete. Figure 24 shows an example of the complete plot of Fig. 21.

\subsection{Results for Professors}

The lab was based on an existing research topic. The professors expected some results, but were surprised by others. Expected results are shown in Figs. 8, 9, or 14. However, when students presented the results, they created self-contained graphics, which were better than expected. The contour plot of the $\mathrm{ON}$ and OFF periods of a mechanical pulse in Figs. 17 and 21 were actually unexpected, which evolved into Fig. 24 Moreover, the result in Fig. 18 introduced a new technique for communication that was never previously published but will be shortly. Based on these quantitative results generated in the lab, the professors re-analyzed the results and completed a manuscript on this topic. Figure 25 shows the results from each round for creating the manuscript. The manuscript has been published as a journal [7]. Noted: with the same teaching technique, the professors also got other published papers [8-9] in the other conference.

\subsection{Survey}

After the class, a survey of the 22 students who took the new lab evaluated their satisfaction with the approach. There are 6 satisfaction questions. The satisfaction questions are asked on comparisons of developing skills with the new lab and other labs. The results are shown in Fig. 26. 95.5\% of students agree that the new lab help them understand how to define scope of problem, $100 \%$ of students agree that they learn to design the experiment form the new lab, 77.3\% of students agree that they learn measurement equipment form the new lab, 91\% of student agree that the lab help them to develop analysis and conclusion skills, and 95\% of student agree that they learn how to present the results. In addition, 91\% of students would recommend other students to take the new lab.

\subsection{Focus Group}

Based on the survey, student feedback was positive. Most students agreed that they had a chance to use new and up-to-date measurement equipment. They had freedom to design and conduct the experiment for this lab while they had to simply follow the guideline for other labs. Moreover, they learned how to analyze, create self-contained graphics, and report the results. Also, the students appreciated the EWH facilities, such as the SMART board and white boards because The SMART board helps them to present their idea and have discussion with the professors. In addition, they felt that what they did on the lab was useful and interesting. The lab has real-world applicability. They also could see that their results were used to write a paper for publication.

However, students complained that they did not have a chance to learn programming the instrument such as LabVIEW devices or Arduino. The lab had only one tactile wristband. When one group worked on the experiment, another group needed to wait. Moreover, the time of the class was too short. They had to spend their extra time to do the lab and the experiment time was too long.

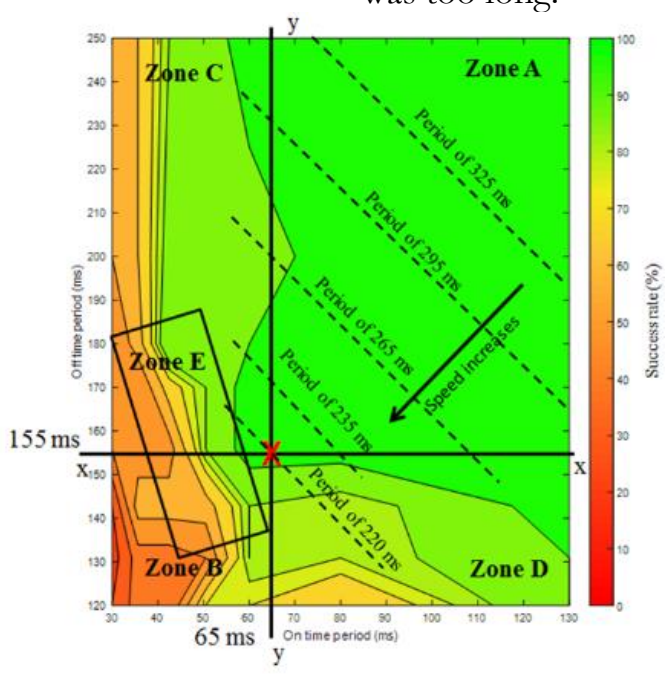

Fig. 24. Example of the complete plot of Fig. 21. 


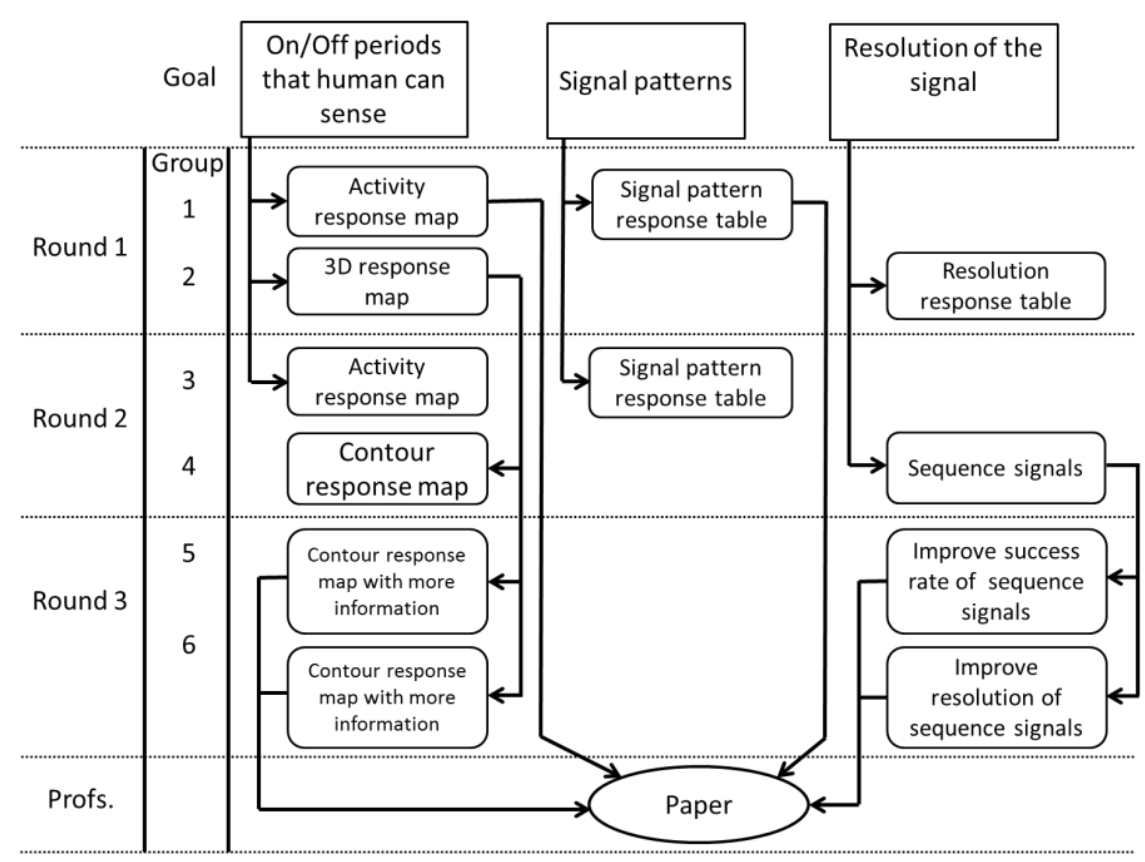

Fig. 25. The results from each round for creating the manuscript.

\section{The New Lab Satisfaction -Rated as Strongly and Somewhat Agree}

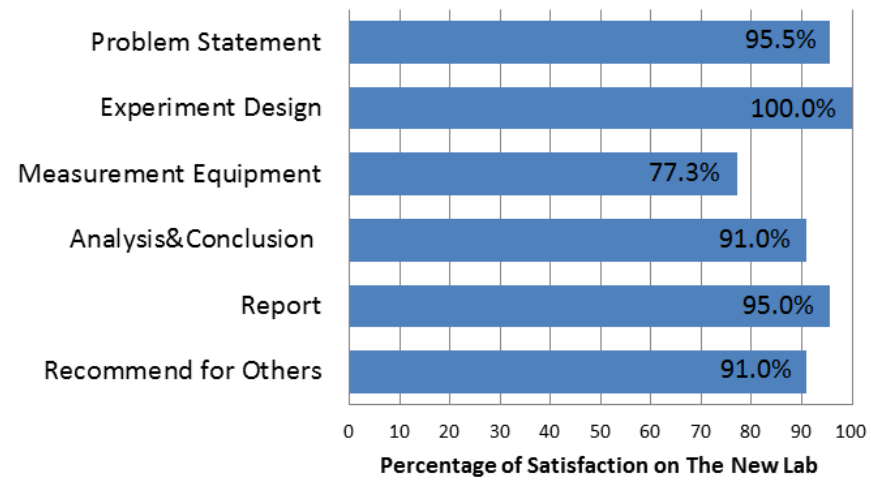

Fig. 26. Student survey on comparison of developed capabilities between the new lab and other labs.

\section{Conclusions}

The new lab has been re-designed for 2103-360 Mechanical Engineering Experimentation and Laboratory II Class. The traditional lab is replaced with the research topic, Developing vibrotactile haptic stimuli based on measured buman capabilities. The questions of the lab are open ended questions. There are many answers to questions, and students need to formulate a good question before attempting to answer it. Students get a challenging lab experience. There is no guideline and clue to answer. Copying last year's labs is impossible. Students learn instrumentation in a way that forces them to think about the problem, develop a method to measure a phenomenon, and draw conclusions about the results. Also, the topic can be a motivating experience for future study.
The new lab takes more effort for professors to create labs, but when results fold directly into research objectives, this becomes an efficient use of time. It is fairly common for professors to ignore undergraduate labs, but this paper shows that with a little bit of effort, these labs can become a significant learning experience for students while providing data for scientific papers.

\section{Acknowledgments}

This Research is funded by Chulalongkorn University: CU_GI_62_05_21_01 


\section{References}

[1] J. B. F. van Erp, "Guideline for the use of vibrotactile displays in human computer interaction," in Proceedings of Eurohaptics, 2002, pp. 18-22.

[2] J. B. F. van Erp, H. A. H. C. van Veen, and C. Jansen, "Waypoint navigation with a vibrotactile waist belt," ACM Transactions on Applied Perception, vol. 2, no. 2, pp. 106-117, Apr. 2005.

[3] K. Tsukada and M. Yasumura, "ActiveBelt: Belt-type wearable tactile display for directional navigation," in UbiComp 2004: Ubiquitous Computing, 2004, vol. 3205, pp. 384-399.

[4] S. Bosman, B. Groenendaal, J. W. Findlater, T. Visser, M. de Graaf, and P. Markopoulos, "GentleGuide: An exploration of haptic output for indoors pedestrian guidance," in Human Computer Interaction With Mobile Devices and Services. Berlin; Heidelberg: Springer, 2003, pp. 358-362.

[5] T. McDaniel, S. Krishna, D. Colbry, and S. Panchanathan, "Using tactile rhythm to convey interpersonal distances to individuals who are blind," in CHI 2009, April 2009, Boston, Massachusetts, USA, pp. 4669-4674.
[6] D. Szymczak, C. Magnusson, and K. RassmusGrohn, "Guiding tourists through haptic interaction: Vibration feedback in the Lund Time Machine," in EuroHaptics 2012, P. Isokoski and J. Springare Eds., 2012, Part II, LNCS 7283, pp. 157-162.

[7] G. Phanomchoeng, R. Chancharoen, and R. Lumia, "Developing vibrotactile haptic stimuli based on measured human capabilities," Virtual Reality, vol. 21, no. 4, pp. 203-212, 2017.

[8] P. Pongpetrarat, J. Arunrat, P. Sangkhaman, P. Nilsumrit, P. Chemhengcharoen, S. Visitsara-at, R. Chanchareon, and G. Phanomchoeng, "Full sphere recognition enhancement with cast shadow images," in The 2017 2nd International Conference on Control and Robotics Engineering, Bangkok, Thailand, April 2017, pp. 222-226.

[9] G. Phanomchoeng and R. Chancharoen, "Projected pattern on three-dimensional objects for image feature classification and recognition," in The 2017 2nd International Conference on Control and Robotics Engineering, Bangkok, Thailand, April 2017, pp. 237241.

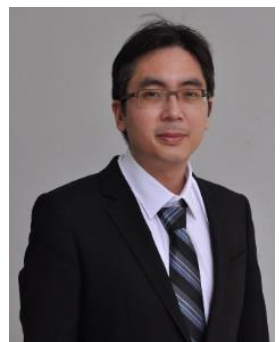

Dr. Gridsada Phanomchoeng received the B.S. degree from Chulalongkorn University, Bangkok, Thailand, in 2002, and the M.S. degree in aerospace engineering and mechanics and the $\mathrm{Ph} . \mathrm{D}$. degree in control science and dynamical systems from the University of Minnesota, Twin Cities, Minneapolis, MN, USA, in 2007 and 2011 respectively.

In 2012, he was a Postdoctoral Researcher in Dr. Rajamani's mechanical engineering laboratory at the University of Minnesota, Twin Cities.Currently, he is a faculty member of Mechanical Engineering at Chulalongkorn University, Bangkok, Thailand.

Dr. Gridsada's research interests include advanced control system design, observer design for nonlinear systems, system identification, applications to automotive systems, energy harvesting and machine vision.

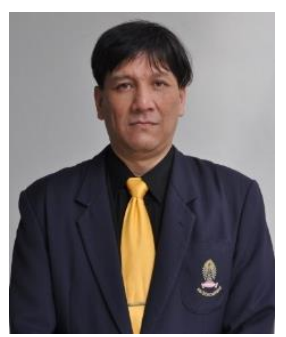

Dr. Ratchatin Chancharoen is currently an Associate Professor at the Mechanical Engineering Department, Chulalongkorn University, Thailand. He received his B.S. degree in mechanical engineering from Chulalongkorn University in 1991, M.S. degree in mechanical engineering from Oregon State University in 1994, and Ph.D. degree in mechanical engineering from Chulalongkorn University in 2000.

He has twenty years experience in robotics research including both manipulators and mobile robots and ten years in teaching both Robotics and Mechatronics at the university level. During these years, he has designed and built more than twenty robots in various configurations and published more than 20 research papers and one text book entitled "Linear Control Systems" (in Thai). He is principal investigator and co-investigator of a number of research grants in robotics and also the manager of a number of industrial projects in design and control. His major research activities involve tele-operation and control of robotics manipulators and mobile robots using various kinds of sensors, especially force and vision. His current research is the design a telerobot, a new type of robot, to work closely with human to do a higher level of tasks. The telerobot is designed with lighter frame, less power consumption, small footprint controller, and higher level of intelligence, compared to the industrial robot, to safely work in our working space. This type of robot will be populated in the near 
future as more complex tasks are demanded. His main research interests are in the field of Robotics and Mechatronics including new parallel robot configuration, new hardware processor, electronics, control algorithm, and intelligence.

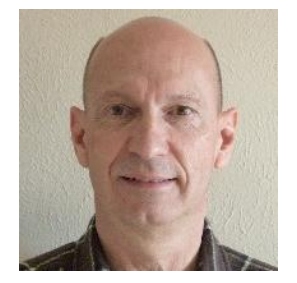

Dr. Ron Lumia received the B.S. degree in electrical engineering from Cornell University, Ithaca, NY, in 1972. He received the M.S. and Ph.D., both in electrical engineering, from the University of Virginia, Charlottesville, VA, in 1977 and 1979, respectively. His technical interests include computer vision, microrobotics, robot control, professional software development, and manufacturing.

He has been a Professor in the Mechanical Engineering Department at the University of New Mexico, Albuquerque, NM since 1994. From 1986-94, he was Group Leader of the Intelligent Control Group at the National Institute of Standards and Technology (NIST). Previously, he held academic positions at Ecole Superieure d'Ingenieurs en Electrotechnique et Electronique (ESIEE) in Paris, France, Virginia Tech in Blacksburg, VA, and the National University of Singapore. He was a Fulbright Scholar at the Indian Institute of Science in Bangalore during Fall 2008. He is spending the 2015-16 Academic Year on sabbatical at Chulalongkorn University, Bangkok, Thailand, also as a Fulbright Scholar.

Professor Lumia remains active in IEEE Conference organization, serving IROS 2003 as Chair of Special Sessions, IROS 2007 as Finance Chair, ICRA1997 and 2006 as Exhibits Chair and ICRA 2010 as Finance Chair. He is currently Treasurer of the IEEE Robotics and Automation Society. 